ISSN 1112-9867

http://www.jfas.info

\title{
SENSITIVITY PATTERN RECOGNITION AND VARIABLENESS OF \\ COMPETITIVE ADOLESCENT SOCCER RELATIVE PERFORMANCE INDICATORS
}

A. B. H. M. Maliki ${ }^{1,2}$, M. R. Abdullah ${ }^{1,2,{ }^{*}}$, H. Juahir ${ }^{1}$, R. M. Musa ${ }^{2}$, S. M. Mat-Rasid ${ }^{1}$, A. Adnan $^{2}$, N. A. Kosni ${ }^{2}$, V. Eswaramoorthi ${ }^{3}$ and N. Alias ${ }^{3}$

${ }^{1}$ East Coast Environmental Research Institute, University of Sultan Zainal Abidin, Gong Badak Campus, 21300 Terengganu,, Malaysia

${ }^{2}$ Faculty of Applied Social Sciences, University of Sultan Zainal Abidin, Gong Badak Campus, 21300 Terengganu, Malaysia

${ }^{3}$ Faculty of Health Sciences, School of Rehabilitation Science, Universiti Sultan Zainal Abidin, 21300 Terengganu, Malaysia

Published online: 08 August 2017

\begin{abstract}
This study aims to examine the most dominant variables multilaterally with specifically focus on the differences and inter-individually variability in different soccer positions. 184 male youth soccer players were recruited in Malaysia soccer academy (average age $=15.2 \pm 2.0$ ) underwent to, physical fitness test, anthropometric, maturity, motivation and level of skill related soccer. Principal Component Analysis (PCA) revealed multilateral dominant variables for soccer player's meanwhile Multivariate Analysis of Variance (MANOVA) discovered the significant inter-groups/position variability. As a result, practitioners and players have an option for their monitoring parameters (33 to 18 parameters). Variability of players positioning characteristics highlighted the weakness and strongest ability to be more competitive in the game.
\end{abstract}

Keywords: pattern recognition; principal component analysis; soccer.

Author Correspondence, e-mail: razali896@yahoo.com

doi: http://dx.doi.org/10.4314/jfas.v9i2s.35 


\section{INTRODUCTION}

Football or soccer is the most popular game, globally played by male and female, kids, youths and children at all exceptional stages of opposition. Soccer performance depends on upon a multilateral factors inclusive of technical, tactical, physiological and mental additives. Soccer is irregular in nature since it requires change of movements in every 3-5 s and is also a physically demanding sport which require excessive movements including turns, jumps, sprints, high-speed runs, tackle and multiple quick responses [1]. Several research were carried out to expand a model primarily based at the most considerable variables in particular game, which could enhance the impact of the training [2-4] or to differentiate among players of various stage of participation [5,38]. Without an exception especially for soccer, this method is needed for the fortification of the performance to compete in the opposition.

Prediction model of the soccer ought to be carried out multilaterally from the physiological, psychological, tactical, technical and anthropometric elements of the soccer [6]. Benefits of the prediction model with the aid of the usage of multilaterally components will assist to choose variables that were precise predictors, mainly for soccer and the prediction model of soccer performance which can be based at the most crucial variables related to the soccer [39]. With the aid of approaching prediction model, those techniques are sensitively discriminate across stage of participation in soccer [39]. At some point of the validation process of the model, training of the reliability of the model and lastly cross-validation of the model through multivariate analysis with the intention to discover the accuracy and reliability of the model primarily based at the particular components that notably changed in the soccer performance [7]. Due to the benefits from those model, it should be implemented to all the area in regard to the each country specifically in an Asian soccer setting that's specific and unique handiest for Asian characteristics of soccer players.

Based on the obtainable result from previous study, it is expected that inter-individual variability were significantly differ within playing position specifically on the spending time in walking and jogging and also distance covered [8]. Correspondingly, the positioning of players in soccer has uncovered the inter-individual variability which include a high variation in body mass among the midfielders [9]. Variation of the required attribute on specific 
position in soccer will benefits the tactical and technicality of the game. Attribute information of individual ability on each players will projected the suitable tactical formation of the game. It has been previously deliberated that minimal heterogeneity remains in the anthropometric qualities and physiological variables of elite players, where several factors can incline the success of the players [10]. An integration of the multilateral factors namely growth and maturity, motivation, and skill related to soccer will contribute comprehensive information on the recognizing variables related to soccer with regard to the players positioning [40-41]. Therefore, the aims of this study was twofold: (a) to identify the most dominant variables (anthropometric, growth and maturity, physical fitness, technical skills and motivation) related to soccer relative performance; and (b) to determine the differences of the most dominant variables related to soccer relative performance at playing different positions-goalkeepers (GK), defenders (D), midfielders (M) and strikers (S). Precisely, this study generally aims to examine the most dominant variables multilaterally with specifically focus on the differences and inter-individually variability in different positions.

\section{METHODOLOGY}

\subsection{Participants}

A random sampling method applied to the current research, which is comprising all the players across all soccer school and academies in Malaysia. Exclusion conditions for the participants applied when there is an injury and participate in other local and national competition. From the exclusion of the participants selection, overall of 223 adolescent soccer players (mean age $=15.2 \pm 1.6$ years) were joined to participate in this study which is drawn from two Malaysian state adolescent soccer academy and six from Malaysia school center of soccer.

All the procedure, protocols, equipment and instrument of the research were approved by the university Human Research Ethics Committee (UniSZA/02/1/2016/Jil. 207). The objective of the study is informed to the managers of the academies, parents, and guardians of the players. Consent forms were signed by the players and the written approval was received. Soccer relative performance can be defined as anthropometric factors (chronological age, height, 
weight, sitting height, body fat skinfold, girth and maturity), physical fitness elements (predicted $\mathrm{VO}_{2} \mathrm{max}$, sit and reach, agility, sit up, sergeant jump and speed at three various distances) and psychological components (task and ego orientation). Correspondingly, soccer technical skill was operationally defined as a fundamental technical skill in soccer (long pass, short pass, ball control and shooting).

\subsection{Battery Test Procedure}

\subsubsection{Anthropometrics}

Anthropometric testing was measured which encompasses of chronological age, weight, height, sitting height, body fat, girth and maturity. Chronological age was measured in months starting from the date of each players was born until the testing date. A regulated automated digital scale was used to evaluate the body mass (nearest $0.01 \mathrm{~kg}$ ). Meanwhile, a wall-mounted automated stadiometer was utilized to calculate the stature to the nearest $0.5 \mathrm{~cm}$. Meanwhile, sitting height was measured from the top of the head to the seated bottoms and was automate recorded to the nearest $0.5 \mathrm{~cm}$ [11].

Body fat was calculated via skinfold method by applying four sites of measurement namely triceps, biceps, subscapular and suprailiac to the nearest $0.1 \mathrm{~mm}$ whereas the girth were measured on the calf circumference (cc) and the medial upper arm circumference (muac) by using non-stretchable tape. All the procedure and protocol of the body fat and girth testing were obtained twice and the mean value score were used for the final score as followed as ISAK protocol [12].

Meanwhile, pubescence of the players was measured according to the sexual development phase of pubic hair which was adopted from criteria by [14] and was utilized as an indicator of the prominence of sexual maturity [13].

\subsubsection{Physical Fitness}

Muscular strength test was performed consequently to the suggested technique for physical fitness assessments [15]. Players lie on the mat with their knees bended at the correct edges, while situating both knees on the floor. The player's held their hands against their trunk, where they ought to remain completely all the way through the test. In the meantime, an evaluator held the player's feet put on the floor. Players sat up until their elbows touch their knees, then 
returning to the floor. The routine was conducted as many times as possible in a period of $60 \mathrm{~s}$. The quantity of the finished sit-ups is totaled and listed by the assistant. The test was measured at one time and is credited to the effect of weariness.

The multistage $20-\mathrm{m}$ carry run test was actualized to procure the player's maximal oxygen take-up [16]. Each player continued running for whatever time allotment they could bear the cost of until could no more keep pace with the speed of the tape. The results from the test for each player were communicated as an expected VO2max and is finished by checking the last level and finished shuttle number when the players willfully surrendered from the test. Regardless of the way that the drills and motivation of the players may impact their scores, it is a genuine test in evaluating the maximum oxygen take-up and can be conducted with an extensive number of players which minimize the costs and time.

Linear sprint speed was assessed more than $30 \mathrm{~m}$. Infrared speed trap (Brower Timing System) was situated toward the begin line $(0 \mathrm{~m})$ and $5 \mathrm{~m}, 10 \mathrm{~m}$ and $20 \mathrm{~m}$ at a height of approximately $0.5 \mathrm{~m}$ off the ground [17]. Players began the test from a standing start at a separation of $0.3 \mathrm{~m}$ behind the original timing gate before initiating the test taking and after the researcher began a countdown. The players were advised to hold from running at maximal speed all through the full time span of the sprint test. The players were advised to maintain the maximal pace until passing the marker on which the guide stood The execution times were recorded at situated at 5, 10 and $20 \mathrm{~m}$ respectively. No less than 4 min of rebuilding were given between reiterations. A minimum of 4 minutes was given between the repetitions to the players.

A Vertec testing contraption (M-F Athletic Co., Cranston, Rhode Island) was used to choose the vertical jump stature $(\mathrm{cm})$ which is a genuine and strong measure of leg explosive power [18]. A tester was prepared to surface this test and was adjusted to the height of the colour-coded plastic vanes with the end goal that it is aligned to the competitor's standing achieve stature. The vane stack was then lifted so the players would not jump higher or lower than the adjustment of the vanes. Using a countermovement, the players flexed the knees, ankles and hips and then swung the arms in an upward movement, touching the highest possible vane with the fingers of the predominant hand. Three jumps with 40-60 seconds rest between each jump were conducted by each player. The sit and reach test was employed to 
measure the flexibility of the hamstrings and lower back [19]. Two trials were completed by the players performed two trials and the best one was selected for further examination.

The 505 agility test was utilized to assess agility and the procedures was performed as previously explained [20]. Pointers are set up 5 and 15 meters from a line marked on the ground. players keep running from the $15 \mathrm{~m}$ marker close to the line (keep running in separation to build speed) and through the $5 \mathrm{~m}$ markers, turns on line and keeps running back over the $5 \mathrm{~m}$ markers. The time is reported utilizing infrared speed trap (Brower timing framework) from when the players initially go through the $5 \mathrm{~m}$ marker and ceased when they return through these markers. Two maximal tries are attempted by each player and the fastest time was recorded for further investigation. The players ought to be urged not to exceed the line by much as this will expand their time.

\subsubsection{Skill Assessment}

Technical skills tests such as ball control, short pass and long pass were administered to the players. The basic skills were selected and implemented according to the guidelines provided by (F-MARC battery test), which are developed by previous researcher [21]. This test permits appraisal of facilitated dribbling under assessment of speed and time pressure. The assessment of accuracy and coordination in passing a moving ball was assessed using a short pass test. Meanwhile, the evaluation of shooting power over a long distance and passing precision are measured using the long pass test. Shooting (dead ball) test permits the evaluation of exactness and coordination in shooting from a dead ball, and shooting from a pass (foot) test permits appraisal of precision and coordination in shooting from a ground pass.

\subsubsection{Instrumentation}

Additionally, the Task and Ego Orientation in Sport Questionnaire (TEOSQ) was employed to identify the degree of the player's mastery and performance were adopt from the previous study [22]. This motivational questionnaire comprises of 13 items with two concept which measure the athlete's orientation whether it is ego-oriented or task-oriented in sports involvement. The questionnaire was transformed into Malay Language using back-translation technique, and it is proficient and in addition discovered exceptional reliability in the sports aspect [23]. The determination subscale of the internal consistency with Cronbach alpha 
reliability coefficients of task (0.82) and ego (0.71) respectively were tested. In the questionnaire, there are seven items which measure task (e.g., "I work really hard) while there are six items in measuring ego (e.g., "I can do better than my friends). The feedback are then ranked on a 5-point Likert scale which ranges from 1 (strongly disagree) to 5 (strongly agree).

\subsection{Data Analysis}

\subsubsection{Pre-Processing Data}

A total of 7359 sets of matrices data (223 observations x 33 variables) was computed in this analysis. In prior of the main data analysis, data were tested for the normality, missing and outlier data by using box plot and Kolmogorov-Smirnov [24]. As a result, the total of the missing and error data was minuscule $(\sim 3 \%)$. Thus, nearest neighbor technique was applied in this study to replace the missing and error data because of its easiness and effectiveness. This technique was tested the gap between each section of the missing data and the closest section to it [25]. It's formulated as shown in the Equation (1), whereas $y$ is the interpolant, $x$ is the interpolant of the each section. In the meantime, $y_{1}$ and $x_{1}$ are the range of sections for starting point of the gap and the opposite for ending sections of the gap is $y_{2}$ and $x_{2}$.

$y=y_{1}$, if $x \leq x_{1}+\frac{x_{2}-x_{1}}{2}$ or; $y=y_{2}$, if $x \leq x_{1}+\frac{x_{2}-x_{1}}{2}$

\subsection{Statistical Analysis}

Principal component analysis/factorial analysis is an outstanding and robust pattern recognition method that is frequently offer an available understanding into the most principal parameters. It dissimilarities of relative performance components that illuminate the whole data set by reducing massive parameters with a significant smallest amount loss of the whole data [26-29]. The principle component (PC) can be quantified by Equation (2) whereas $z$ is the component score, $a$ is the component loading, $x$ is the measured approximation of the parameter, $i$ is the component quantity, $j$ is the participants quantity and $m$ is the accumulative quantity of parameters.

$z_{i j}=a_{i 1} x_{1 j}+a_{i 2} x_{2 j}+\ldots+a_{i m} x_{m j}$

The factorial analysis (FA) is generally connected with a strategy to transform a significant, complicated information outline and propositions a capable method for recognizing similarities among variables or observations. The PCs produced by PCA are not 
stereotypically promptly interpreted; therefore, it is recommended to turn the PCs by applying varimax rotation [30]. Varimax rotation determines by the PCs with eigenvalues more than 1 are noticed as significant for the determination of instituting new variables called varimax factors (VFs). The number of VFs integrated by varimax rotation is correspondent to some variables as per essential components and can integrate unobservable, hypothetical and latent variables. The fundamental idea of FA is conversed as shown in the Equation (3) whereas $z$ is the dignified value of the variable, $a$ is the factor loading, $f$ is the factor score, $e$ is the residual errors or other source of variation, $i$ is the observations number, $j$ is the parameters number and $m$ is the total number of the factors.

$z_{i j}=a_{f 1} f_{1 i}+a_{f 2} f_{2 i}+\ldots+a_{f m} f_{m i}+e_{f i}$

In this study, output of the PCA/FA was smeared to the standardized data sets (33 variables), resulting act as dependable variation parameters on the dissimilarities between players positioning in adolescent soccer.

Nevertheless, data were analyzed using a factorial analysis of variance (ANOVA) to examine the dissimilarities interaction of soccer relative performance indicators at different positional role. Where a significant differences was detected, posthoc comparisons were made by using Tukey's HSD test for pair wise comparisons as shown in the Equation (4). Whereas HSD is honestly significant difference, $\mathrm{M}_{1}$ and $\mathrm{M}_{2}$ is replicate to the mean values, $\mathrm{MSw}$ is for mean square measurement and lastly $\mathrm{n}$ is the number per mean.

$\mathrm{HSD}=\frac{\mathrm{M}_{1}-\mathrm{M}_{2}}{\sqrt{\mathrm{MS}_{\mathrm{W}}\left[\frac{1}{\mathrm{n}}\right]}}$

For all analyses, significance was accepted at $\mathrm{p}<0.05$. XLSTAT 2016 add-in software was utilized to conduct all analyses.

\section{RESULTS AND ANALYSIS}

Table 1 projected the descriptive statistics of player's characteristics on 33 selected test battery as projected as minimum, maximum, mean $(\mathrm{M})$ and standard deviation (SD) values for all variables on 223 Malaysia youth soccer players. 
Table 1. Descriptive statistics criteria in 33 selected parameters related to soccer on 223

Malaysia youth soccer players

\begin{tabular}{|c|c|c|c|c|c|}
\hline Variable & Observations & Min & $\operatorname{Max}$ & $\mathbf{M}$ & SD \\
\hline Biological age & 223 & 142.83 & 219.46 & 183.10 & 19.14 \\
\hline Weight & 223 & 26.90 & 90.50 & 56.51 & 9.47 \\
\hline Height & 223 & 128.60 & 190.60 & 166.06 & 8.05 \\
\hline Sitting Height & 223 & 38.60 & 98.40 & 86.92 & 5.57 \\
\hline Biceps & 223 & 2.80 & 12.30 & 4.10 & 1.14 \\
\hline Triceps & 223 & 4.50 & 24.80 & 7.77 & 2.26 \\
\hline Sabscapul & 223 & 4.50 & 28.80 & 8.30 & 2.33 \\
\hline Spiliac & 223 & 4.50 & 45.40 & 8.11 & 3.63 \\
\hline MUAC & 223 & 2.30 & 34.60 & 24.73 & 2.89 \\
\hline $\mathrm{CC}$ & 223 & 3.70 & 44.00 & 34.95 & 3.57 \\
\hline Maturity & 223 & 1.00 & 5.00 & 3.85 & 0.79 \\
\hline S\&R & 223 & 0.00 & 27.00 & 13.25 & 5.18 \\
\hline SJ & 223 & 2.69 & 198.00 & 64.30 & 14.85 \\
\hline V. Sit Up & 223 & 2.00 & 7.00 & 5.90 & 0.96 \\
\hline $505 \mathrm{~A}$ & 223 & 1.64 & 2.98 & 2.37 & 0.25 \\
\hline Speed $5 \mathrm{~m}$ & 223 & 0.36 & 1.55 & 0.79 & 0.16 \\
\hline Speed $10 \mathrm{~m}$ & 223 & 1.00 & 2.21 & 1.53 & 0.19 \\
\hline Speed $20 \mathrm{~m}$ & 223 & 1.50 & 4.08 & 2.85 & 0.29 \\
\hline FI & 223 & -1.55 & 6.43 & 0.48 & 0.84 \\
\hline $\mathrm{VO}_{2} \mathrm{mx}$ & 223 & 29.93 & 63.73 & 47.38 & 7.68 \\
\hline Run w/ball & 223 & 1.93 & 7.58 & 4.55 & 1.12 \\
\hline Juggling (foot) & 223 & 5.00 & 52.00 & 38.83 & 11.23 \\
\hline Juggling Body & 223 & 3.00 & 9.00 & 7.39 & 1.97 \\
\hline Speed Dribbling & 223 & 16.91 & 29.30 & 20.95 & 2.33 \\
\hline Long Passing & 223 & 0.00 & 12.00 & 3.85 & 2.78 \\
\hline Short Passing & 223 & 1.00 & 15.00 & 10.00 & 3.53 \\
\hline
\end{tabular}




\begin{tabular}{cccccc} 
Shooting TR (Dead Ball) & 223 & 0.00 & 18.00 & 3.70 & 2.95 \\
Shooting TL (Dead Ball) & 223 & 0.00 & 13.00 & 3.57 & 2.91 \\
Shooting From a Pass (Foot) & 223 & 0.00 & 26.00 & 8.18 & 5.57 \\
Heading (md_post) & 223 & 0.00 & 18.00 & 9.02 & 4.52 \\
Heading (sd_post) & 223 & 0.00 & 18.00 & 7.25 & 4.24 \\
task & 223 & 17.00 & 70.00 & 59.78 & 7.68 \\
Ego & 223 & 6.00 & 58.00 & 32.91 & 10.89 \\
\hline
\end{tabular}

Prior to the main data analysis, it is affirmed that one of the correlations between the variables is significantly different as reported by the Bartlett's test of sphericity $(p=0.0001)$. At the same time, the data was confirmed to be appropriate for further analysis by Kaiser-Meyer-Olkin measure of sampling adequacy (0.768) as shown on the Table 2 even though 505A (0.460), FI (0.483) and Task (0.465) test revealed lacking of sampling adequacy. Based on this evident, it is enabled to proceed for further main analysis.

Table 2. Sampling adequacy of KMO test

\begin{tabular}{cc}
\hline Biological age & 0.846 \\
Weight & 0.767 \\
Height & 0.746 \\
Sitting Height & 0.781 \\
Biceps & 0.821 \\
Triceps & 0.817 \\
Subscapular & 0.841 \\
Spiliac & 0.807 \\
MUAC & 0.867 \\
CC & 0.824 \\
Maturity & 0.907 \\
S\&R & 0.871 \\
SJ & 0.837 \\
V. Sit Up & 0.672 \\
$505 A$ & 0.460
\end{tabular}




\begin{tabular}{cc} 
Speed 5m & 0.667 \\
Speed 10m & 0.753 \\
Speed 20m & 0.795 \\
FI & 0.483 \\
VO2mx & 0.885 \\
Run w/ball & 0.708 \\
Juggling (foot) & 0.804 \\
Juggling Body & 0.582 \\
Speed Dribbling & 0.820 \\
Long Passing & 0.933 \\
Short Passing & 0.792 \\
Shooting TR (Dead Ball) & 0.687 \\
Shooting TL (Dead Ball) & 0.586 \\
Shooting From a Pass (Foot) & 0.664 \\
Heading (md_post) & 0.802 \\
Heading (sd_post) & 0.716 \\
task & 0.465 \\
Ego & 0.582 \\
\hline $\mathbf{0 . 7 9 4}$ & \\
\hline
\end{tabular}

PFA theoretically divided by 2 phase which, in first phase functionally integrated exploratory method and continue with confirmatory method. First phase primarily employed with 33 selected parameters related to soccer performance. Exploratory phase (EP) revealed that only nine components out of 33 selected parameters were identified by the EP of PFA as the most influence components due to the higher eigenvalues greater than $1(>1)$ as aforementioned in the standardize method of measurement before. Nevertheless, cumulative variability of the nine parameters influence by $66.62 \%$ total of the variance as projected on Table 3 . The main components contributes for the variability if the variances dominated by PC-1 and PC-2 with $20.13 \%$ and $14.01 \%$, correspondingly and followed by the rest of the parameters. Hereafter, output from the EP of PFA, will further analyze in second phase by employing nine 
components as a domain factors. Fig. 1 depicts the scree plot which graphically discovered the performance of the cumulative variability of the variances based on each principles factors depending on the performances of the eigenvalue output.

Table 3. Descriptive of the exploratory of PCA

\begin{tabular}{cccccccccc}
\hline & F1 & F2 & F3 & F4 & F5 & F6 & F7 & F8 & F9 \\
\hline Eigenvalue & 6.643 & 4.622 & 2.442 & 2.064 & 1.425 & 1.346 & 1.207 & 1.197 & 1.040 \\
Variability (\%) & 20.129 & 14.005 & 7.399 & 6.254 & 4.318 & 4.079 & 3.658 & 3.626 & 3.152 \\
Cumulative \% & 20.129 & 34.134 & 41.533 & 47.788 & 52.106 & 56.184 & 59.843 & 63.469 & 66.621 \\
\hline
\end{tabular}

Further analysis were continue by reanalyzed the PFA for the second phase with employing the sets of confirmatory identified nine principle factors computed with varimax rotation method. Table 4 exposed the sensitivity of the parameters selection with projected the most influences factor loading (standardized at above 0.700) on each parameters/variables horizontally sorted with dominant factors (D1 to D9). It can be observed from the Table 1, D1 is dominated by four parameters (weight $=0.730$; height $=0.800$; maturity $=0.701$ and $\mathrm{SJ}=$ 0.721). Similarly, D2 revealed four dominant parameters include biceps (0.881), Triceps (0.909), Sbscapul (0.880) and Spiliac (0.902). Nevertheless, D3 until D9 highlighted with single domain component namely dead ball shooting parameters (D3) $6.447 \%$, speed (D4) $8.687 \%$, aerobic capacity (D5) $8.757 \%$, agility (D6) $4.301 \%$, flexibility (D7) $3.869 \%$, task orientation (D8) $3.807 \%$ and side post heading (D9) 4.081 respectively. Total variability of the variance on each factors from the most dominant parameters overall contribute $66.621 \%$ accordingly. 


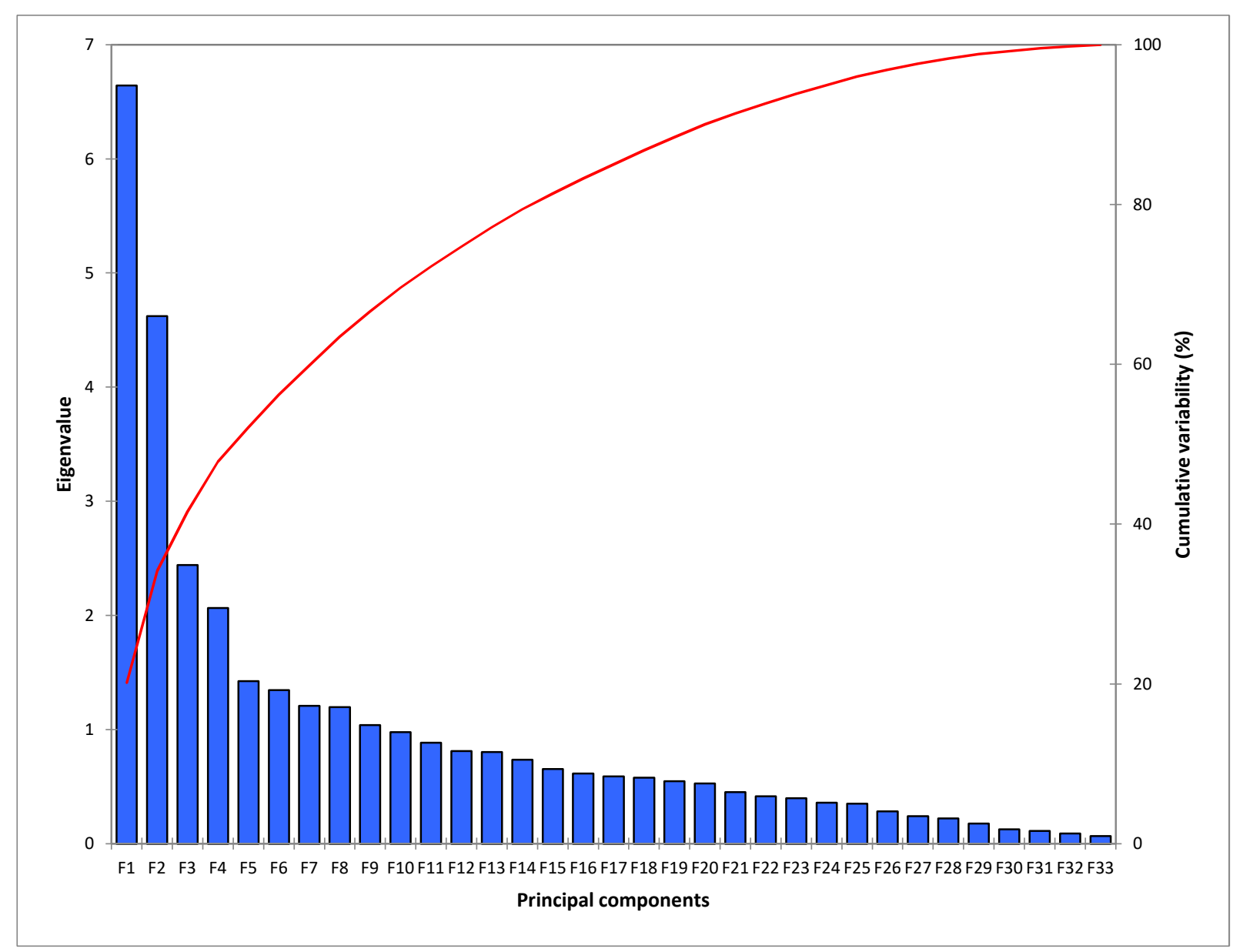

Fig.1. Scree plot of the descriptive eigenvalue

Comparison of differences test were examined to determine the magnitude of the differences toward position in soccer based on the most dominant parameters. Table 5 exhibit the analysis of the variance on pairwise comparison between groups on soccer. Initially, 18 variables were selected as an input for the analysis of variance. Table 5 also tabulated the most significant magnitude of the differences between groups. It revealed only eight variables show the magnitude of the differences between groups namely, weight, height, bicep, tricep, subscapular, suprailliac, $\mathrm{VO}_{2} \max$ (aerobic capacity) and side post heading. Consecutively, the magnitude of the significant variables between groups were graphically projected in box and whisker plot as shown in Fig. 2.

Based on the Fig. 2, there is a significant dissimilarities exist on weight between players position with a confidence interval of $95 \%$. Goalkeepers (GKs) were significantly heavier, taller, more on percentage of body fat on three site (bicep, subscapular and suprailliac), but significantly lower on $\mathrm{VO}_{2 \max }$ compare to midfielders (M) $\mathrm{p}<0.05$ respectively. 
Table 4. Factor loading of soccer relative performance after varimax rotation

\begin{tabular}{|c|c|c|c|c|c|c|c|c|c|}
\hline Variables & D1 & D2 & D3 & D4 & D5 & D6 & D7 & D8 & D9 \\
\hline Biological age & 0.614 & 0.041 & -0.045 & -0.248 & 0.444 & -0.184 & -0.348 & -0.067 & 0.001 \\
\hline Weight & 0.730 & 0.500 & -0.094 & -0.121 & 0.090 & 0.006 & 0.180 & -0.050 & -0.050 \\
\hline Height & 0.800 & 0.203 & -0.056 & -0.112 & 0.090 & 0.009 & 0.123 & -0.023 & -0.004 \\
\hline Sitting Height & 0.682 & 0.239 & -0.128 & -0.098 & 0.191 & 0.061 & 0.085 & 0.099 & 0.019 \\
\hline Biceps & -0.050 & 0.881 & -0.007 & 0.208 & -0.136 & -0.054 & 0.046 & 0.066 & 0.033 \\
\hline Triceps & -0.036 & 0.909 & 0.010 & 0.123 & -0.069 & -0.009 & 0.019 & 0.013 & 0.003 \\
\hline Sbscapul & 0.244 & 0.880 & -0.059 & 0.026 & 0.059 & -0.032 & -0.100 & 0.003 & 0.024 \\
\hline Spiliac & 0.085 & 0.902 & 0.018 & 0.034 & -0.141 & -0.077 & -0.059 & -0.017 & 0.076 \\
\hline MUAC & 0.562 & 0.583 & -0.059 & -0.121 & 0.059 & 0.093 & 0.130 & 0.001 & -0.050 \\
\hline $\mathrm{CC}$ & 0.444 & 0.456 & -0.160 & -0.276 & 0.208 & 0.073 & 0.256 & -0.113 & 0.037 \\
\hline Maturity & 0.701 & 0.052 & 0.024 & -0.109 & 0.346 & -0.149 & -0.121 & 0.004 & -0.020 \\
\hline$S \& R$ & 0.571 & -0.021 & 0.014 & -0.013 & 0.272 & 0.037 & -0.028 & 0.070 & 0.026 \\
\hline SJ & 0.721 & -0.180 & -0.029 & 0.095 & -0.132 & 0.041 & 0.003 & -0.006 & 0.139 \\
\hline V. Sit Up & 0.134 & 0.007 & -0.025 & -0.054 & 0.145 & -0.028 & 0.860 & -0.037 & -0.042 \\
\hline $505 \mathrm{~A}$ & 0.107 & 0.134 & 0.054 & 0.069 & 0.065 & -0.803 & -0.135 & 0.095 & 0.175 \\
\hline Speed $5 \mathrm{~m}$ & 0.081 & 0.083 & -0.068 & 0.881 & 0.075 & -0.089 & -0.124 & -0.007 & -0.089 \\
\hline Speed $10 \mathrm{~m}$ & -0.213 & 0.054 & -0.031 & 0.859 & -0.214 & 0.090 & 0.085 & -0.051 & 0.040 \\
\hline Speed $20 \mathrm{~m}$ & -0.299 & 0.124 & -0.091 & 0.822 & -0.143 & 0.099 & -0.017 & -0.073 & 0.017 \\
\hline FI & 0.038 & 0.166 & -0.038 & 0.066 & -0.204 & -0.044 & -0.107 & -0.112 & 0.523 \\
\hline $\mathrm{VO} 2 \mathrm{mx}$ & 0.276 & -0.105 & -0.135 & -0.138 & 0.713 & -0.104 & 0.133 & 0.038 & -0.032 \\
\hline Run w/ball & -0.223 & 0.035 & -0.443 & 0.103 & -0.213 & -0.093 & 0.286 & 0.398 & 0.092 \\
\hline Juggling (foot) & 0.189 & 0.007 & -0.149 & -0.141 & 0.671 & 0.182 & -0.015 & -0.050 & 0.184 \\
\hline Juggling Body & 0.148 & 0.034 & -0.117 & 0.199 & 0.163 & 0.664 & -0.223 & 0.096 & 0.162 \\
\hline Speed Dribbling & -0.152 & 0.158 & -0.258 & 0.330 & -0.658 & 0.154 & 0.039 & 0.122 & -0.018 \\
\hline Long Passing & 0.416 & -0.112 & 0.219 & -0.189 & 0.370 & 0.036 & -0.007 & -0.024 & 0.161 \\
\hline Short Passing & 0.142 & 0.002 & 0.023 & 0.269 & 0.654 & 0.128 & 0.126 & 0.121 & -0.006 \\
\hline oting TR (Dead Ball) & -0.090 & -0.002 & 0.744 & -0.011 & -0.037 & 0.064 & -0.092 & -0.007 & 0.146 \\
\hline
\end{tabular}




\begin{tabular}{cccccccccc} 
Shooting TL (Dead Ball) & -0.004 & -0.023 & $\mathbf{0 . 7 4 4}$ & -0.021 & -0.044 & -0.063 & 0.026 & -0.132 & -0.109 \\
Shooting From Pass (Foot) & -0.130 & -0.028 & 0.669 & -0.082 & -0.010 & -0.183 & 0.069 & 0.057 & 0.106 \\
Heading (md_post) & 0.114 & -0.044 & 0.328 & -0.225 & 0.250 & 0.231 & 0.060 & 0.210 & 0.470 \\
Heading (sd_post) & 0.037 & -0.045 & 0.097 & -0.061 & 0.246 & -0.046 & 0.047 & -0.095 & $\mathbf{0 . 7 2 4}$ \\
task & 0.063 & 0.033 & -0.080 & 0.007 & 0.139 & -0.086 & -0.081 & $\mathbf{0 . 7 4 2}$ & 0.008 \\
Ego & 0.018 & -0.021 & 0.000 & -0.164 & -0.153 & 0.139 & 0.034 & 0.599 & -0.332 \\
Eigenvalue & 6.643 & 4.622 & 2.442 & 2.064 & 1.425 & 1.346 & 1.207 & 1.197 & 1.040 \\
Variability (\%) & 13.787 & 12.884 & 6.447 & 8.687 & 8.757 & 4.301 & 3.869 & 3.807 & 4.081 \\
Cumulative \% & 13.787 & 26.671 & 33.118 & 41.805 & 50.562 & 54.863 & 58.733 & 62.540 & 66.621 \\
\hline
\end{tabular}

On the other hand, GKs also significantly low on $\mathrm{VO}_{2 \max }$ and heading from side post [heading (sd_post)] but heavier compare to striker (S) p $<0.05$ respectively. Meanwhile, for the outfield players, defender (D) were heavier, taller and more on percentage of body fat on two sites (subscapular and suprailliac) compare to midfielder $(\mathrm{M}) \mathrm{p}<0.05$. Details of the players positioning differences on each parameters were further discuss.

Table 5. Analysis of variance on the pairwise comparison on each group based on the most significant parameters in soccer

\begin{tabular}{ccccccc}
\hline Variables & GK & $\mathbf{D}$ & $\mathbf{S}$ & $\mathbf{M}$ & $\mathbf{P r}>\mathbf{F}$ & Significant \\
\hline Weight & $61.664 \mathrm{c}$ & $59.001 \mathrm{bc}$ & $55.346 \mathrm{ab}$ & $52.893 \mathrm{a}$ & 0.000 & Yes \\
Height & $169.461 \mathrm{~b}$ & $168.152 \mathrm{~b}$ & $165.178 \mathrm{ab}$ & $163.256 \mathrm{a}$ & 0.000 & Yes \\
Biceps & $4.604 \mathrm{~b}$ & $4.254 \mathrm{ab}$ & $3.956 \mathrm{ab}$ & $3.871 \mathrm{a}$ & 0.020 & Yes \\
Triceps & $8.426 \mathrm{a}$ & $8.166 \mathrm{a}$ & $7.620 \mathrm{a}$ & $7.237 \mathrm{a}$ & 0.030 & Yes \\
Sbscapul & $9.183 \mathrm{~b}$ & $8.752 \mathrm{~b}$ & $8.027 \mathrm{ab}$ & $7.701 \mathrm{a}$ & 0.007 & Yes \\
Spiliac & $9.533 \mathrm{~b}$ & $8.723 \mathrm{~b}$ & $7.856 \mathrm{ab}$ & $7.147 \mathrm{a}$ & 0.009 & Yes \\
Maturity & $4.000 \mathrm{a}$ & $3.988 \mathrm{a}$ & $3.714 \mathrm{a}$ & $3.724 \mathrm{a}$ & 0.085 & No \\
SJ & $71.391 \mathrm{a}$ & $63.667 \mathrm{a}$ & $64.595 \mathrm{a}$ & $62.684 \mathrm{a}$ & 0.097 & No \\
V. Sit Up & $5.870 \mathrm{a}$ & $6.085 \mathrm{a}$ & $5.833 \mathrm{a}$ & $5.750 \mathrm{a}$ & 0.164 & No \\
$505 \mathrm{~A}$ & $2.335 \mathrm{a}$ & $2.375 \mathrm{a}$ & $2.386 \mathrm{a}$ & $2.367 \mathrm{a}$ & 0.880 & No \\
Speed 5m & $0.841 \mathrm{a}$ & $0.771 \mathrm{a}$ & $0.808 \mathrm{a}$ & $0.794 \mathrm{a}$ & 0.238 & No \\
Speed 10m & $1.613 \mathrm{a}$ & $1.512 \mathrm{a}$ & $1.524 \mathrm{a}$ & $1.533 \mathrm{a}$ & 0.156 & No
\end{tabular}




\begin{tabular}{ccccccc} 
Speed 20m & $2.934 \mathrm{a}$ & $2.819 \mathrm{a}$ & $2.843 \mathrm{a}$ & $2.876 \mathrm{a}$ & 0.337 & No \\
VO2max & $43.254 \mathrm{a}$ & $46.610 \mathrm{ab}$ & $49.212 \mathrm{~b}$ & $48.439 \mathrm{~b}$ & 0.009 & Yes \\
Shooting TR (Dead Ball) & $3.043 \mathrm{a}$ & $3.890 \mathrm{a}$ & $3.500 \mathrm{a}$ & $3.789 \mathrm{a}$ & 0.630 & No \\
Shooting TL (Dead Ball) & $2.435 \mathrm{a}$ & $3.720 \mathrm{a}$ & $3.905 \mathrm{a}$ & $3.553 \mathrm{a}$ & 0.234 & No \\
Heading (sd_post) & $5.174 \mathrm{a}$ & $7.280 \mathrm{ab}$ & $8.476 \mathrm{~b}$ & $7.158 \mathrm{ab}$ & 0.027 & Yes \\
task & $61.826 \mathrm{a}$ & $60.134 \mathrm{a}$ & $59.952 \mathrm{a}$ & $58.684 \mathrm{a}$ & 0.339 & No \\
\hline
\end{tabular}

\section{DISCUSSION}

The aimed of this study was to recognize the pattern variability of the competitive youth soccer relative performance. The main discovery of this study was that recognizing the soccer relative performance pattern indicators elicited only 18 parameters out of 33 parameters discovered as the most significant parameters. Nevertheless, sensitivity analysis of recognizing each parameters systematically identify accordingly based on the most domain factors to the less domain factors. Furthermore, it was found that players on different position demanding specific variability in anthropometric, growth and maturity, physical fitness and skill respectively.

\subsection{Sensitivity Analysis of Parameters}

Recognizing a good players is merely subjective with a large spectrum of classification. The existence of the multivariate analysis, especially factor analysis (FA) applied as a sensitivity analysis of pattern recognition soccer relative performance discovered a new spectrum on soccer player's assessment with more objective and specific information. The application of the sensitivity analysis of the parameters in this study is crucial for practitioners and researcher. A cautious methodology should be enforced by researcher when recapping physical characteristics, certain motor abilities and physiological variable, which are connected to enhanced performance. The presence of sensitivity analysis revealed the most dominant factors accordingly based on the domain factors. Finding of the current study suggesting the most dominant factors related for competitive youth soccer players accordingly from the dominant factor namely anthropometrics, motor abilities, physical fitness test and motivation (see Table 4). This results includes an assessment variability, which ought to 
impart alert among the practitioners while assessing the ability of players to be successful in soccer. Achievement in soccer is according to the multilateral measurements (physiological, physical, technical, psychological, social and technical) and practitioners need to observe the characteristics of the players from a holistic aspect as compared from a reductionist aspect.

Currently, there is no evident confirmation that specific battery tests possess predictive value in either development in sport or talent detection [31]. It has been revealed that among success soccer player, distinction in anthropometric, growth and maturity, physical fitness and motor abilities occur, and consequently it is not possible to differentiate individual requirement for success with a high level of soccer relative performance [32]. Based on the current finding from this study, it is elicited the hierarchical multilateral importance's sort by their domain (see Table 4). Therefore, this finding suggest for the practitioner and player to reconsider their training program following the importance's of the components. Nevertheless, findings suggest the importance's of each component in soccer related for the assessment regardless for the monitoring and improvement.

\subsection{Inter Groups Variability}

Based on the output of the sensitivity analysis (trim down of 33 to 18 parameters), further analysis were computed to determine the physical characteristics differences among players position. The findings revealed that there are significant dissimilarities between the positions of the players and their physical characteristics. Furthermore, the study elicited the demand of the significant multilateral attribute on each position. This study suggesting that goalkeeper (GK) are heavier, taller and fatter but low in aerobic capacity $\left(\mathrm{VO}_{2 \max }\right)$ and heading compared to defender (D), midfielder (M) and striker (S), $\mathrm{p}<0.05$ respectively.

This anthropometric characteristics has already been defined in adult and adolescent soccer GKs by prior researcher [33]. Similarly, finding of the current study in concordance with previous study supporting that GKs should have a large body size (including body fat) in order to stop the ball from entering the goal and advantages in aerial ability in order to prevent conceding [33]. Nature of the positioning of the GKs, aerobic capacity should be lower compared to outfield players, demonstrating the adequacy minimum performance demand for GKs. The rest of the parameters related to the soccer, GKs show no significant difference with 
outfield players suggesting that all the parameters are required to excel in soccer.

It is also noticeable that body size was higher in the D players compared to the $M$ (weight, height, subscapular and suprailliac). This finding suggesting that D required to have large body size in order to beat their opponent with the ability of the man to man marking, tackling and also heading in the aerial should give an advantages ability [34]. Although $M$ shows lower performance in body size which isolated their ability, it reflected greater performance for $\mathrm{M}$ in other point of view. For instance, midfielder with a free role and playmaker, creating chances and build the game is the criteria needed for them and if the players have large body size it will limit and effect their skill ability in execution of the tactical game [35]. Unambiguously to soccer, players' positional variability illustrates the tactical regions where they play during games [36], and may allow for the stratification of the performance of players from different level of skills [37].
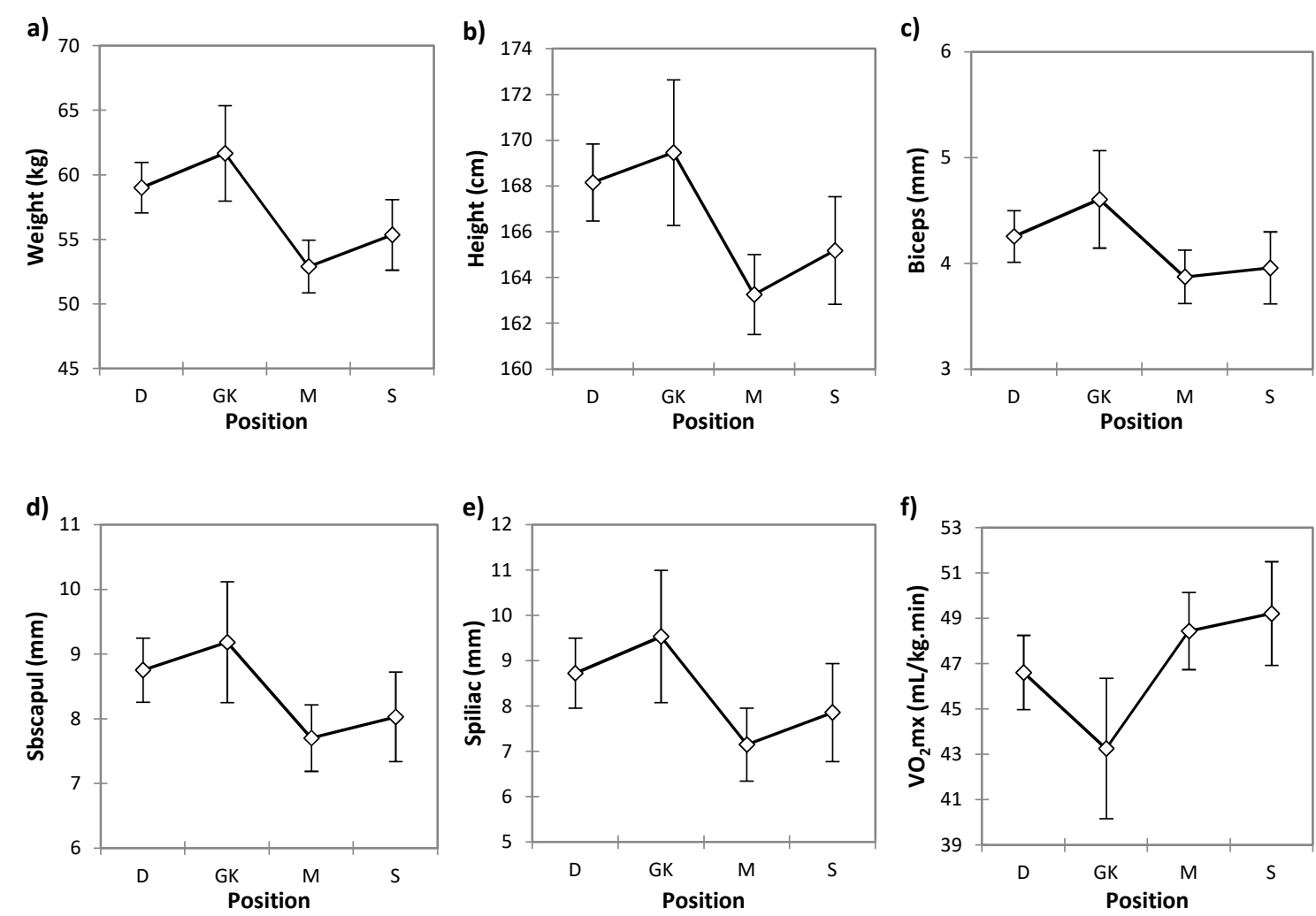
g)

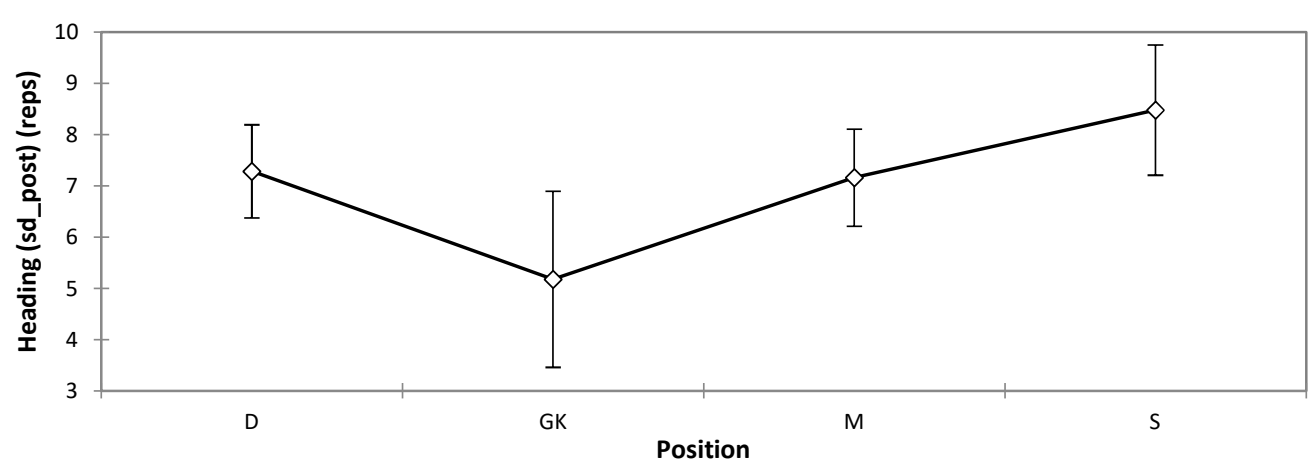

Fig.2. Mean value plot of the soccer relative performance indicators on each soccer positions In the meantime, finding from this study supported with the previous study that indicated that striker is thinner, endure more than GK and skillful in heading compared to goalkeeper but not for defenders [36-37]. For instance, finding of the current study might suggesting that, for a pacey striker and a free role forward should have the great ability of pace, acceleration, speed and can endure approximately for 90 minutes. Intimation of the optimum weight with great ability of aerobic capacity conjoining of the finishing touch will offer an individual advantages. Execution of striker or forward individuality ability with a good tactical application might advancing the defenders and finally beat the goalkeeper.

\section{CONCLUSION}

In this study, an integration of factorial analysis (FA) followed by analysis of variance technique was functionally to precisely recognized the significant parameters related to soccer indicators, and finally identification of the players positioning distinction on the multilateral significant indicators. Major finding of the current study suggesting the soccer indicators can be trimed down to only certain indicators. Practitioners and players have an option for their monitoring parameters from 33 parameters untill only 18 parameters.

Nevertheless, output from the significant parameters related to soccer performance were followed up by stratification on the variability on the players performance. It is recommended to identify the differences attribute related to players positioning in regard to repositioing of the players, recognizing spesific attribute on each position and for the purpose of the players monitoring. The results from the characteristics of players positioning can be effectively utilized by sport coaches and strength and conditioning coaches. This allows the players to 
obtain maximum benefit from every training program which are conducted for players monitoring purposes.

Practitioner and players especially need to know their ability (weakness and strongest) by using this method in order to excel in soccer. Meanwhile, coaches can apply this method for the purpose of repositioning of the players based on the player's ability as a result will affect their tactical and technical training program.

\section{ACKNOWLEDGEMENTS}

The authors would like to thank Malaysia Fundamental Research Grant Scheme [FRGS/1/2016/SS05/UniSZA/02/1] for the financial support and all soccer players and coaches in Malaysia soccer academies for the supporting of this study.

\section{REFERENCES}

[1] Oberacker L M, Davis S E, Haff G G, Witmer C A, Moir G L. The Yo-Yo IR2 test: Physiological response, reliability, and application to elite soccer. Journal of Strength and Conditioning Research, 2012, 26(10):2734-2740

[2] Aasa U, Jaric S, Barnekow-bergkvist M, Johansson H. Muscle strength assessment from functional performance tests: Role of body size. Journal of Strength and Conditioning Research, 2003, 17(4):664-670

[3] Geladas N D, Nassis G P, Pavlicevic S. Somatic and physical traits affecting sprint swimming performance in young swimmers. International Journal of Sports Medicine, 2005, 26(2):139-144

[4] Girold S, Calmels P, Maurin D, Milhau N, Chatard J C. Assisted and resisted sprint training in swimming. Journal of Strength and Conditioning Research, 2006, 20(3):547-554

[5] Ugarkovic D, Matavulj D, Kukolj M, Jaric S. Standard anthropometric, body composition, and strength variables as predictors of jumping performance in elite junior athletes. Journal of Strength and Conditioning Research, 2002, 16(2):227-230

[6] Abdullah M R, Musa R M, Maliki A B H M, Kosni N A, Suppiah P K. Role of psychological factors on the performance of elite soccer players. Journal of Physical 
Education and Sport, 2016, 16(1):170-176

[7] Abdullah M R, Hairi M S N A, Musa R M, Maliki A B H M, Kosni N A. Prediction of specific physical characteristic and fitness related variables on cardiovascular endurance among some selected uniform arm units of University Sultan Zainal Abidin, Malaysia. Movement, Health and Exercise, 2017, 6(1):21-29

[8] Reilly T, Bangsbo J, Franks A. Anthropometric and physiological predispositions for elite soccer. Journal of Sports Sciences, 2000, 18(9):669-683

[9] Hencken C, White C. Anthropometric assessment of Premiership soccer players in relation to playing position. European Journal of Sport Science, 2006, 6(4):205-211

[10] Reilly T, Williams A M, Nevill A, Franks A. A multidisciplinary approach to talent identification in soccer. Journal of Sports Sciences, 2000, 18(9):695-702

[11] Mellemkjaer L, Christensen J, Frederiksen K, Baker J L, Olsen A, Sørensen T I, Tjønneland A. Leg length, sitting height and postmenopausal breast cancer risk. British Journal of Cancer, 2012, 107(1):165-168

[12] Marfell-Jones M J, Stewart A D, de Ridder J H. International standards for anthropometric assessment. Wellington: International Society for the Advancement of Kinanthropometry, 2012

[13] Falaschetti E, Hingorani A D, Jones A, Charakida M, Finer N, Whincup P, Lawlor D A, Davey S G, Sattar N, Deanfield J E. Adiposity and cardiovascular risk factors in a large contemporary population of pre-pubertal children. European Heart Journal, 2010, 31(24):3063-3072

[14] Tanner J. M. Growth at adolescence. Oxford: Blackwell Scientific Publications, 1962

[15] Noguchi T, Demura S, Takahashi K. Relationships between sit-ups and abdominal flexion strength tests and the thickness of each abdominal muscle. Advances in Physical Education, 2013, 3(2):84-88

[16] Ernesto C, Da Silva F M, Pereira L A, De Melo G F. Cross validation of different equations to predict aerobic fitness by the shuttle run 20 meters test in Brazilian students. Journal of Exercise Physiology Online, 2015, 18(1):46-55

[17] Russell M, Tooley E. Anthropometric and performance characteristics of young male 
soccer players competing in the UK. Serbian Journal of Sports Sciences, 2011, 1(4):155-162

[18] Haff G. G., Triplett N. T. Essentials of strength training and conditioning. Illinois: Human Kinetics, 2015

[19] Mayorga-Vega D, Merino-Marban R, Viciana J. Criterion-related validity of sit-and-reach tests for estimating hamstring and lumbar extensibility: A meta-analysis. Journal of Sports Science and Medicine, 2014, 13(1):1-14

[20] Hoffman J. Norms for fitness, performance, and health. Illinois: Human Kinetics, 2006

[21] Rosch D, Hodgson R, Peterson L, Graf-Baumann T, Junge A, Chomiak J, Dvorak J. Assessment and evaluation of football performance. American Journal of Sports Medicine, 2000, 28(5_suppl):29-39

[22] Abdullah M R, Maliki A B H M, Musa R M, Kosni N A, Juahir H, Haque M. Multi-hierarchical pattern recognition of athlete's relative performance as a criterion for predicting potential athletes. Journal of Young Pharmacists, 2016, 8(4):463-470

[23] Abdullah M R, Maliki A B H M, Musa RM, Kosni N A, Juahir H. Intelligent prediction of soccer technical skill on youth soccer player's relative performance using multivariate analysis and artificial neural network techniques. International Journal on Advanced Science, Engineering and Information Technology, 2016, 6(5):668-674

[24] Al-Odaini N A, Zakaria M P, Zali M A, Juahir H, Yaziz M I, Surif S. Application of chemometrics in understanding the spatial distribution of human pharmaceuticals in surface water. Environmental Monitoring and Assessment, 2012, 184(11):6735-6748

[25] Abdullah M R, Musa R M, Kosni N A, Maliki A B H M, Karim M S, Haque M. Similarities and distinction pattern recognition of physical fitness related performance between amateur soccer and field hockey players. International Journal of Life Science and Pharma Research, 2016, 6(4):35-46

[26] Juahir H, Zain S M, Aris A Z, Yusof M K, Samah M A, Mokhtar M. Hydrological trend analysis due to land use changes at Langat River Basin. Environment Asia, 2010, 3:20-31

[27] Mun'im Mohd Han N, Latif M T, Othman M, Dominick D, Mohamad N, Juahir H, Tahir N M. Composition of selected heavy metals in road dust from Kuala Lumpur City Centre. Environmental Earth Sciences, 2014, 72(3):849-859 
[28] Aris A Z, Abdullah M H, Praveena S M, Yusoff M K, Juahir H. Extenuation of saline solutes in shallow aquifer of a small tropical island: A case study of Manukan Island, North Borneo. Environment Asia, 2010, 3(Special issue):84-92

[29] Toriman M E, Gasim M B, Yusop Z, Shahid I, Mastura S S, Abdullah P, Jaafar M, Aziz N A, Kamarudin M K, Jaafar O, Karim O. Use of 137 Cs activity to investigate sediment movement and transport modeling in river coastal environment. American Journal of Environmental Sciences, 2012, 8(4):417-423

[30] Musa R M, Abdullah M R, Maliki A B H M, Kosni N A, Haque M. The application of principal components analysis to recognize essential physical fitness components among youth development archers of Terengganu, Malaysia. Indian Journal of Science and Technology, 2016, 9(44):1-6

[31] Lidor R, Côté J, Hackfort D. ISSP position stand: To test or not to test? The use of physical skill tests in talent detection and in early phases of sport development. International Journal of Sport and Exercise Psychology, 2009, 7(2):131-146

[32] Abdullah M R, Maliki A B H M, Musa R M, Kosni N A, Juahir H, Mohamed S B. Identification and comparative analysis of essential performance indicators in two levels of soccer expertise. International Journal on Advanced Science, Engineering and Information Technology, 2017, 7(1):305-314

[33] Ziv G, Lidor R. Physical characteristics, physiological attributes, and on-field performances of soccer goalkeepers. International Journal of Sports Physiology and Performance, 2011, 6(4):509-524

[34] Abdullah M R, Musa R M, Maliki A B H M, Kosni N A, Suppiah P K. Development of tablet application based notational analysis system and the establishment of its reliability in soccer. Journal of Physical Education and Sport, 2016, 16(3):951-956

[35] Schmidt A. Analyzing complex dynamical systems: Artificial neural networks contribute new insight concerning optimal athletic techniques and tactics. Research Quarterly for Exercise and Sport, 2016, 87(S1):S19-S20

[36] Couceiro M S, Clemente F M, Martins F M L, Machado J A T. Dynamical stability and predictability of football players: The study of one match. Entropy, 2014, 16(2):645-674 
[37] Silva P, Aguiar P, Duarte R, Davids K, Araújo D, Garganta J. Effects of pitch size and skill level on tactical behaviours of association football players during small-sided and conditioned games. International Journal of Sports Science and Coaching, 2014, 9(5):993-1006

[38] Wilson R L. Ranking college football teams: A neural network approach. Interfaces, 1995, 25(4):44-59

[39] Lockie R G, Murphy A J, Knight $\mathrm{T}$ J, de Jonge X A. Factors that differentiate acceleration ability in field sport athletes. Journal of Strength and Conditioning Research, 2011, 25(10):2704-2714

[40] Brocherie F, Girard O, Forchino F, Al Haddad H, Dos Santos G A, Millet G P. Relationships between anthropometric measures and athletic performance, with special reference to repeated-sprint ability, in the Qatar national soccer team. Journal of Sports Sciences, 2014, 32(13):1243-1254

[41] Zuber C, Conzelmann A. The impact of the achievement motive on athletic performance in adolescent football players. European Journal of Sport Science, 2014, 14(5):475-483

\section{How to cite this article:}

Maliki ABHM, Abdullah MR, Juahir H, Musa RM, Mat-Rasid SM, Adnan A, Kosni NA, Eswaramoorthi V, Alias N.Sensitivity pattern recognition and variableness of competitive adolescent soccer relative performance indicators. J. Fundam. Appl. Sci., 2017, 9(2S), 539-562. 